P1-13

\title{
MEASUREMENT OF VACUUM SUCTION FORCE ON DIVERSELY CONFIGURED VERTICAL OUTER WALLS OF BUILDINGS
}

\author{
Young-Bog Ham $^{1}$, Byung-Ju Lim ${ }^{1}$, Chang-Dae Park ${ }^{1}$, Ji-Suk Gu${ }^{1}$, \\ Dae-Geun $\mathrm{Kim}^{2}$, and Se-Hyeong Jeon ${ }^{3}$ \\ ${ }^{1}$ Department of Energy Systems, Korea Institute of Machinery \& Materials, Daejeon, Korea \\ ${ }^{2}$ Department of R\&D Center, Poonglim Co., Ltd, Seoul, Korea \\ ${ }^{3}$ Innotems Innovation Systems Co., Daejeon, Korea \\ *Corresponding author (bzoo77@,kimm.re.kr)
}

\begin{abstract}
Though vacuum suction pads are able to fasten items of working equipment such as gondolas easily and without causing damage to a building's outer wall, their necessary suction force should be designed by considering various conditions such as wind force, the loads of each item of working equipment, and suction capacity. Suction force is changed by the internal vacuum pressure of pads, and the materials and shapes of an outer wall's surface have a considerable influence on vacuum pressure.

In this study, we measured the vacuum suction force of pads on walls configured of various materials and shapes.
\end{abstract}

Keywords: Vacuum Suction Force, Suction Pads, Vertical Outer Wall, Wall Shape, Gondola, High-rise Building

\section{INTRODUCTION}

The outer walls of high-rise buildings are made of various materials such as steel, red block, marble, glass, and so forth, and their surfaces can contain many grooves of irregular shapes and sizes. Table 1 presents the diverse materials used in the outer walls of buildings, as reported in previous studies ${ }^{[1]}$. The outer walls of high-rise buildings require regular maintenance including cleaning and painting. Gondola systems are used to carry on platforms the workers who conduct maintenance work on the outer walls of high-rise buildings. However, for super-high-rise buildings, i.e., higher than 30 stories, it is very difficult to perform such work on their outer walls using a gondola due to external disturbances including squalls. To perform this kind of work on outer walls using gondolas, considerable attachment force (to the wall) is required, taking into consideration the external loads and work loads, so vacuum pads are used to apply the force.
Table 1. Various outer wall materials

\begin{tabular}{|c|l|}
\hline Type & \multicolumn{1}{|c|}{ Materials } \\
\hline A & $\begin{array}{l}\text { Wood, stone, concrete, red block, glass, ceramic, } \\
\text { plastic, fiber, metal, paper }\end{array}$ \\
\hline B & Stone, block, tile, glass \\
\hline C & $\begin{array}{l}\text { Aluminum composite panel, stone, porcelain } \\
\text { enamel panel, red block, cement }\end{array}$ \\
\hline
\end{tabular}

Dong Gwang L., et al. developed and tested a robot system using vacuum suction technology for cleaning the window panes of a building's outer walls ${ }^{[2]}$. Kun Chan S., et al. designed a suction unit for a robot system which can climb up irregular vertical surfaces ${ }^{[3]}$. Siyoul J conducted a study on the design of a vacuum suction pad which can provide a uniform contact shape in large-scale imprinting ${ }^{[4]}$. However, robots traveling on vertical walls have limitations in terms of the shape of the walls and their adhesive force ${ }^{[5-7]}$. Therefore, the vacuum suction ability with the various wall shapes should be evaluated and applied in the outer wall work system. 
In this paper, a testing apparatus is developed to test the maximum adhesive forces of suction pads on various vertical wall surfaces according to pressure change. In addition, the vacuum pressure according to the change of pressure was measured for comparison with the adhesive forces required for safe working on various walls.

\section{TEST EQUIPMENT}

\subsection{TEST EQUPMENT SPECIFICATIONS}

Fig. 2 shows the test equipment fabricated to measure the suction force on various vertical walls. A regulator was provided to maintain a constant pressure to obtain a constant suction force with an ejector-type suction pad $(300 \mathrm{~mm} \times 130 \mathrm{~mm})$. The vertical and horizontal forces were measured using load cells which can measure up to $200 \mathrm{~N}$ of tensile and compressive forces. The pneumatic cylinder was a reciprocating cylinder which can travel bidirectionally. Fig. 1 shows the design drawing of a sliding block which can apply vertical and horizontal forces simultaneously. The sliding block was used to minimize interference between the two axes. The measurement data were collected using LabVIEW. Table 2 presents the specifications of the sub-components of the test equipment.

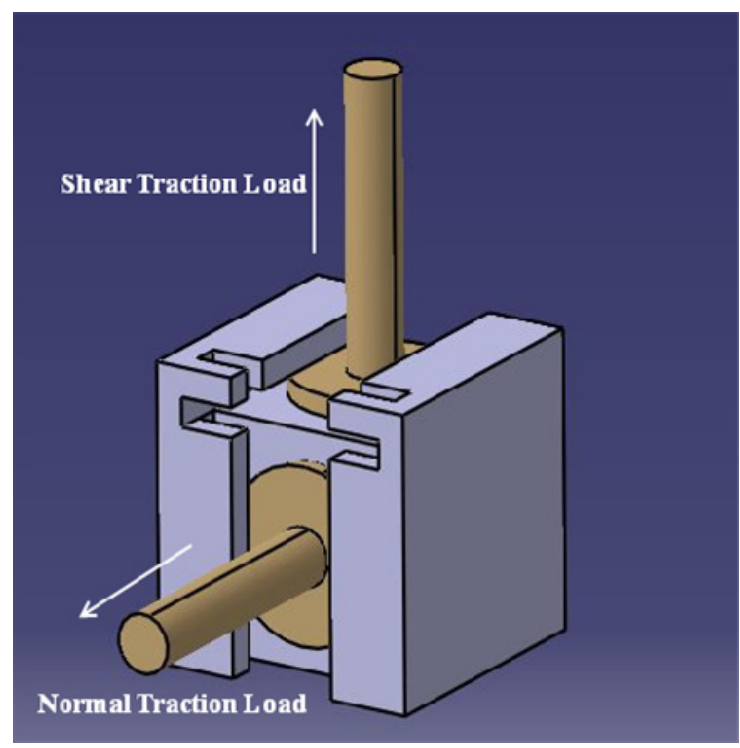

Fig. 1 Sliding block

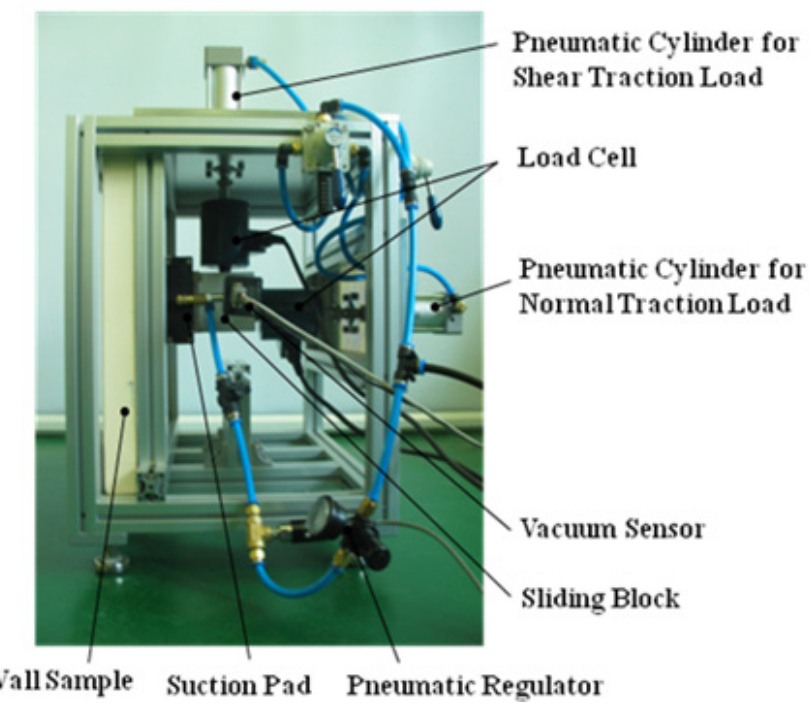

Fig. 2 Vacuum attachment device

Table 2. Specifications of the sub-components

\begin{tabular}{l|l}
\hline Contents & Specifications \\
\hline \hline Wall type & Shape: flat surface \\
\hline Load cell & Range: max. $200 \mathrm{~N}$ \\
\hline Vacuum sensor & $\begin{array}{l}\text {-Range: } 10^{-3} \sim 10^{3} \text { Torr } \\
\text {-Accuracy: } 0.1 \% \text { of indicated } \\
\text { decade }\end{array}$ \\
\hline Pneumatic cylinder & Max pressure : $1 \mathrm{MPa}$ \\
\hline Compressor & Max. pressure: $1 \mathrm{MPa}$ \\
\hline DAQ & Model: NI SCXI $1520(8 \mathrm{ch})$ \\
\hline
\end{tabular}

\subsection{CONFIGURATION OF VERTICAL WALLS}

To simulate the various wall configurations of high-rise buildings, four types of wall samples - including Flat, Step, Rib, and Embossing - were prepared. To conduct the tests under the same conditions as those to which the outer walls of a general high-rise building are subject, the wall samples were fabricated with concrete in the said configurations.

\subsection{FEATURES OF SUCTION PAD}

The suction pad used in this study was based on the ejector principle, whereby the air inside the pad is removed by the ejection of compressed air. Ejectors are used to suck 
up and discharge, transfer or mix gases, liquids or powders. A multi-step nozzle-type VMECA Vacuum cartridge was inserted to maintain constant vacuum pressure even under low and irregular input pressure. The size of the suction pad was $300 \mathrm{~mm} \times 130 \mathrm{~mm}$ and its cross-section 390 $\mathrm{cm}^{2}$. The suction pad was made of flexible sealing foam with multiple holes measuring $12 \mathrm{~mm}$ in diameter and 20 $\mathrm{mm}$ in depth. The suction pad, which could be attached to the irregular surfaces of vertical walls, had a maximum relative vacuum pressure of $555 \mathrm{mmHg}$. Fig. 3 shows the structure of the vacuum suction pad in this study.

Table 3. Shapes of the outer wall samples

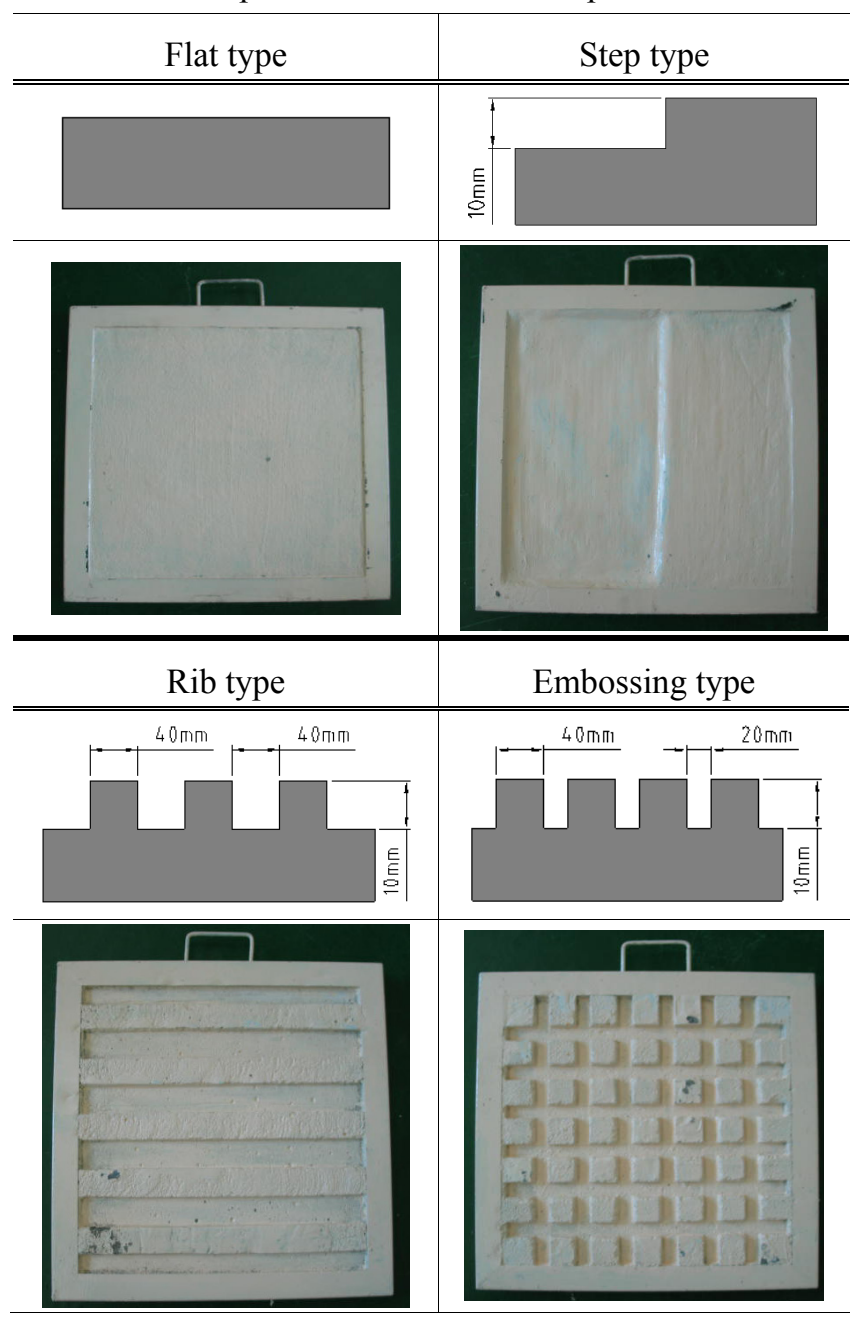

\section{TEST RESULTS}

The pad was attached to the wall's surface and pulled perpendicularly using the cylinder, and the maximum attachment forces of the vacuum suction pad were measured according to surface shapes. Fig. 4 shows the maximum attachment forces according to the shapes of the walls and compressed air pressure. Tables $4 \sim 7$ present the vacuum pressure and maximum attachment forces of the pad according to air pressure.

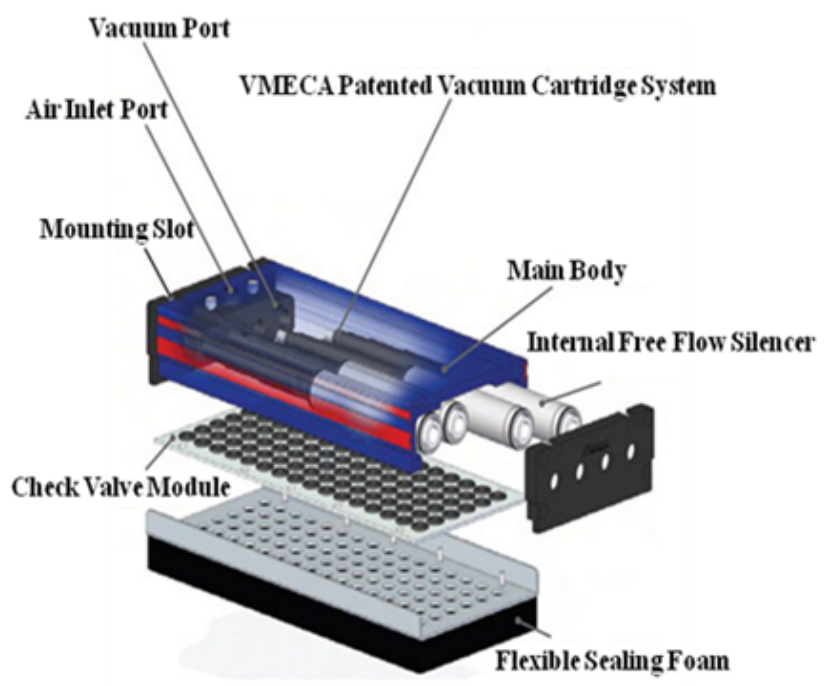

Fig. 3 View of the disassembled vacuum pad

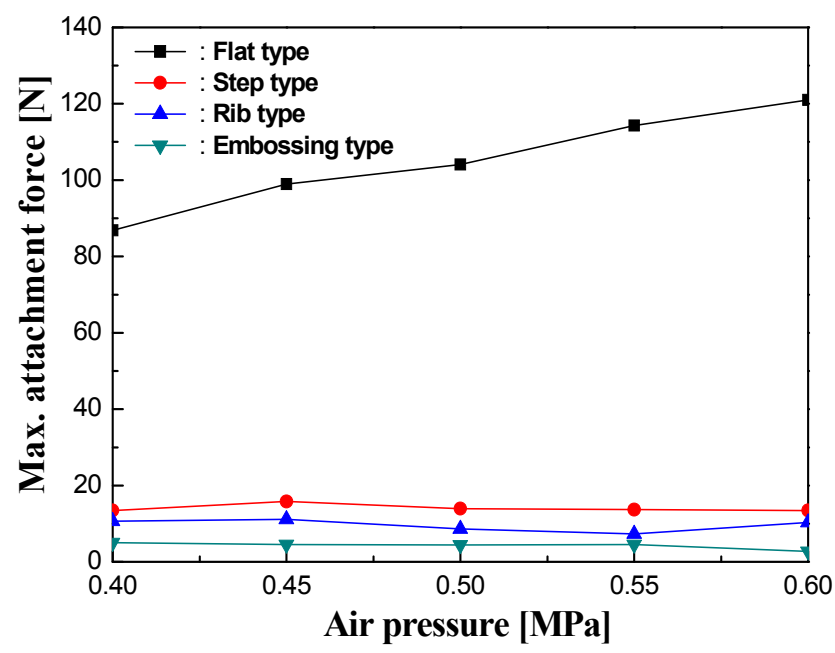

Fig.4 Results graph of max. attachment force with air pressure 
Table 4. Test results of flat-type sample

\begin{tabular}{c|c|c}
\hline $\begin{array}{c}\text { Input Pressure } \\
{[\mathrm{MPa}]}\end{array}$ & $\begin{array}{c}\text { Vacuum Pressure } \\
(-\mathrm{mmHg})\end{array}$ & $\begin{array}{c}\text { Max. Attachment Force } \\
(\mathrm{N})\end{array}$ \\
\hline 0.4 & 355 & 86.87 \\
\hline 0.45 & 421 & 98.99 \\
\hline 0.5 & 500 & 104.12 \\
\hline 0.55 & 585 & 114.27 \\
\hline 0.6 & 605 & 120.97 \\
\hline
\end{tabular}

Table 5. Test results of step-type sample

\begin{tabular}{c|c|c}
\hline $\begin{array}{c}\text { Input Pressure } \\
{[\mathrm{MPa}]}\end{array}$ & $\begin{array}{c}\text { Vacuum Pressure } \\
(-\mathrm{mmHg})\end{array}$ & $\begin{array}{c}\text { Max. Attachment Force } \\
(\mathrm{N})\end{array}$ \\
\hline 0.4 & 232 & 13.44 \\
\hline 0.45 & 259 & 15.81 \\
\hline 0.5 & 259 & 13.94 \\
\hline 0.55 & 280 & 13.64 \\
\hline 0.6 & 245 & 13.44 \\
\hline
\end{tabular}

Table 6 . Test results of rib-type sample

\begin{tabular}{c|c|c}
\hline $\begin{array}{c}\text { Input Pressure } \\
{[\mathrm{MPa}]}\end{array}$ & $\begin{array}{c}\text { Vacuum Pressure } \\
(-\mathrm{mmHg})\end{array}$ & $\begin{array}{c}\text { Max. Attachment Force } \\
(\mathrm{N})\end{array}$ \\
\hline 0.4 & 223 & 10.68 \\
\hline 0.45 & 242 & 11.18 \\
\hline 0.5 & 254 & 8.61 \\
\hline 0.55 & 222 & 7.33 \\
\hline 0.6 & 235 & 10.29 \\
\hline
\end{tabular}

Table 7. Test results of embossing-type sample

\begin{tabular}{c|c|c}
\hline $\begin{array}{c}\text { Input Pressure } \\
{[\mathrm{MPa}]}\end{array}$ & $\begin{array}{c}\text { Vacuum Pressure } \\
(-\mathrm{mmHg})\end{array}$ & $\begin{array}{c}\text { Max. Attachment Force } \\
(\mathrm{N})\end{array}$ \\
\hline 0.4 & 209 & 4.99 \\
\hline 0.45 & 215 & 4.5 \\
\hline 0.5 & 216 & 4.4 \\
\hline 0.55 & 213 & 4.51 \\
\hline 0.6 & 216 & 2.72 \\
\hline
\end{tabular}

The results of the test showed that the ranges of vacuum pressure and attachment forces on the flat-type wall were 355 605 $\mathrm{mmHg}$ and 86.9 121 $\mathrm{N}$, respectively. Those observed for the other types were as follows: 1) step-type: 232 280 $\mathrm{mmHg}$ and 13.4 15.8 N; 2) rib-type: 222 254 $\mathrm{mmHg}$ and 7.3 11.2 $\mathrm{N}$; and 3) embossing-type 209 216 $\mathrm{mmHg}$ and $2.7 \sim 5 \mathrm{~N}$.
On the flat-type wall, the vacuum pressure and attachment force increased proportionally with the increase in the amount of input air pressure. However, for the steptype, while the maximum vacuum pressure was $280 \mathrm{mmHg}$, the maximum attachment force was $15.6 \mathrm{~N}$ at $259 \mathrm{mmHg}$ of vacuum pressure; for the rib-type, while the maximum vacuum pressure was $254 \mathrm{mmHg}$ at $0.5 \mathrm{MPa}$ of air pressure, the maximum attachment force was $11 \mathrm{~N}$ at 242 $\mathrm{mmHg}$ of vacuum pressure; and for the embossing-type wall, the maximum attachment force was obtained at the lowest vacuum pressure of $209 \mathrm{mmHg}$.

\section{CONCLUSIONS}

In this study, testing equipment was fabricated to test and measure the attachment performance of a vacuum suction pad on various configurations of wall surface, i.e., flat, step, rib, and embossing types, formed with concrete material. Since the suction pad was based on the ejector principle, the higher the air pressure, the higher the vacuum pressure.

The test results showed that, while the attachment force on the flat-type wall was $86.9 \mathrm{~N}$ or above, that on the other types of wall were $0.2 \mathrm{~N}$ or less, showing that the performance of the suction pad decreases greatly on irregular wall surfaces. On the step, rib, and embossing types of surfaces, the vacuum pressure in the pad did not increase while the air pressure was being increased, but showed irregular values within a certain range. The attachment performance became increasingly inferior in the flat, step, rib, and embossing types of wall configuration in that order.

The test results show that the performance of the suction pad depends more on the configuration of a wall's surface than on the attachment force generated by air pressure. As such, it could be concluded that the performance of the vacuum suction pad is reliable on flat surfaces, but not on stepped, ribbed or embossed surfaces due to the loss of 
vacuum pressure via their irregular grooves.

The results obtained in this study are expected to be applicable to the design of the suction pads used in wallclimbing robots or wall-work systems including gondolas.

\section{ACKNOWLEDGEMENTS}

The work presented in this paper was funded by the BMRC (Building-Façade Maintenance Robot Research Center), and supported by the Korea Institute of Construction and Transportation Technology Evaluation and Planning (KICTEP) under the Ministry of Land, Transport and Maritime Affairs (MLTM).

\section{REFERENCES}

[1] Ji-Seok, J. et al, "A Study on Choice of the Type of Curtain Wall and the Exterior Material according to Commercial Building Images by using the AHP", Vol. 22(11), pp.89-96, 2006.

[2] Dong-Kwang L. et al, "An instrument of building an outer-wall window-cleaning robot and controller layout using vacuum adsorption technology”, pp. 259-260, 2007. [3] Kunchan S. et al, "Design of an attachment device for robotic systems that climb rugged vertical surfaces", KSPE, pp. 99-100, 2007.

[4] Siyoul Jang, "A study on the enhancement of uniform contact technology for large-scale imprinting with the design of a vacuum gripping pad", Journal of the KSTLE, Vol.24(6), 99. 623-331, 2008.

[5] M. Elliot, W. Norris, J.Xiao, "City-Climber: A new generation of wall-climbing robots", Proceedings of the 2007 IEEE International Conference on Robotics and Automation, 2007.

[6] S. Hirose, A. Nagakubo, R. Toyama, "A machine that can walk and climb on floors, walls and ceilings", International Conference on Advanced Robotics, Vol. 1, pp. 753-758, 1991.

[7] Alan T. et al, "Scaling hard vertical surfaces with compliant microspine arrays", The International Journal of Robotic Research, Vol. 25, pp. 1165-1179, 2006. 